\title{
Female rats in a laboratory display seasonal variation in fecundity
}

\author{
T. M. Lee* and M. K. McClintock \\ Committee on Biopsychology, The University of Chicago, Chicago, IL 60637, U.S.A.
}

\begin{abstract}
Summary. Female laboratory rats housed in controlled environments of two separate laboratories displayed seasonal variation in fecundity. Fecundity peaked between May and August and reached a trough between December and February, as measured by oestrous cycle length, variability and regularity, as well as number of animals mating and the percentage of litters reared to weaning. The percentage of mated animals giving birth remained constant throughout the year. Seasonal variations in the laboratory coincided with the seasonal cycle reported for wild rats in natural conditions. Several environmental variables, e.g. food, water, humidity and airborne factors, were evaluated as putative cues for seasonal variation.
\end{abstract}

\section{Introduction}

Many authors have considered the Norway rat (Rattus norvegicus) to be a model nonseasonal breeder despite evidence to the contrary. Populations of wild female Norway rats in natural conditions have a $30-40 \%$ reduction in prevalence of pregnancy and/or lactation in December through March as compared to June through October (King, 1927; Davis \& Hall, 1951; Leslie, Venables \& Venables, 1952; Davis, 1953; Calhoun, 1962; Telle, 1966). Domestic rat populations which have become feral display the same seasonal cycle of reproduction (Minckler \& Pease, 1938; Calhoun, 1962).

Despite frequent reports by suppliers and researchers of difficulty in maintaining breeding colonies in mid-winter, no-one to date has attempted to document seasonal cycles of fecundity in populations of domestic female rats living in controlled laboratory environments. Presumably this is because light and temperature, the most common seasonal environmental cues, are controlled throughout the year. Nonetheless, under these controlled laboratory conditions, male laboratory rats display seasonal variation in physiological measures of pineal, pituitary and gonadal activity (Mock, Kamel, Wright \& Frankel, 1975; Mock \& Frankel, 1978; 1980; Balemans, Bary, Legerstee \& van Benthem, 1980; Illnerova \& Vanecek, 1980; Berger, 1981; Kafka, Wirz-Justice \& Naber, 1981; Ahlers, Ahlersova, Daxnorova, Toropila \& Smajda, 1982; Ahlersova, Ahlers, Toropila \& Smajda, 1982; Vanecek \& Illnerova, 1982; Prechel, Audhya \& Schlesinger, 1983; Wong et al., 1983). However, since testicular size and sperm index are maintained throughout the year, it has generally been assumed that all other aspects of male reproductive competence are also maintained, but this proposition has not been tested systematically.

We considered it likely that female rats also have seasonal variation in pineal and endocrine function that would affect reproductive competence, while maintaining ovarian cycles. To test the possibility that female rats would undergo seasonal variation in reproductive competence, data were collected in two different laboratories on seasonal variations in fertile ovarian cycles, mating resulting in successful pregnancy, and the number of viable litters produced.

\footnotetext{
* Present address: Department of Psychology, University of California, Pere

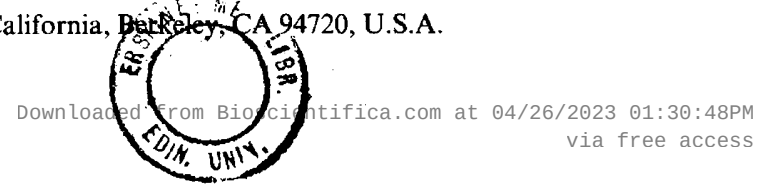




\section{Materials and Methods}

The work was conducted over 2 years in two separate laboratories located in buildings $0.5 \mathrm{~km}$ apart. Ovarian cyclicity is studied routinely in one laboratory and maternal behaviour in the other. Data were based on the colony records of the two laboratories. In both laboratories, access to animals was restricted to a small number of animal care and research personnel who were the same throughout the study years. The animals from both laboratories were housed in cages of similar size and two rooms of similar size containing 50-150 animals.

\section{Fertility measures}

One aspect of fertility is the frequency of ovulation. Individuals with short ovarian cycles have more opportunities for conception because they ovulate more frequently in the same period than do those with long cycles. Therefore, in one laboratory, fertility was measured by oestrous cycle length, variance and regularity.

Data were recorded for 24 months from 5 cohorts of virgin Sprague-Dawley rats $(\mathrm{N}=30$ individuals generating 1018 cycles, and chosen randomly from an all-female colony of 200). To avoid the confounding effects of age, data were collected daily from each cohort of animals when they were reproductively mature and before the onset of reproductive senescence (4-9 months of age; Gerall, Dunlap \& Sonntag, 1980; J. LeFevre \& M. K. McClintock, unpublished observations). Longitudinal records for each animal permitted an accurate assessment of an individual's average oestrous cycle length, variability and regularity. Each cohort entered the study at different times of the year at 3-5-month intervals, and thus age was randomly distributed across the seasons (e.g. summer (June July), 7.00 \pm 0.50 months of age; winter (December-January), $6.98 \pm 0.42$ months of year; N.S., Mann-Whitney U test).

Rats were grouped ( 5 per cage) or singly housed in colony rooms with lighting of $14 \mathrm{~h}$ light: $10 \mathrm{~h}$ dark at $21 \pm 2{ }^{\circ} \mathrm{C}$ temperature, and the relative humidity varied from 35 to $80 \%$ across the year. Fresh air was drawn into the laboratory and heated or cooled by a central steam unit, moved through the rooms at 10-15 room changes per hour, and exhausted $100 \%$ to the outside.

All animals met the traditional requirements in the rat for categorization as having ovarian cycles (a minimum of 3 cycles in each month of study; a range of 3-7 cycles per month was possible for any individual). The length of each female's cycle was determined from the cell content of a daily lavage (McClintock, 1983), and mean cycle length was determined for each female for each month of the study. Variability in mean oestrous cycle length was calculated for each individual from each month of data (Variability Index $=1 / \mathrm{s}$.d. cycle length; the inverse of the s.d. is used so that higher index values would correspond to higher fertility).

In addition, we present a measure of oestrous cycle regularity, the tendency for a female to have consecutive oestrous cycles of the same length within a given period. The regularity index (RI) was defined as $1-$ (no. of different cycle lengths/total no. of cycles observed) and was calculated for each individual from each month of data. Because animals with regular cycles are more likely to mate and produce litters (Gerall \& Dunlap, 1973; Gerall et al., 1980), and because regular cycles are more likely to be ovulatory (Butcher \& Page, 1981; M. K. McClintock, unpublished data), higher regularity scores are indicative of increased fertility. The theoretical range of the RI is 0 to 1 , but given the number of cycles exhibited by each individual in our monthly sample, the RI value could range from 0.0 to 0.86 . The regularity index is different from traditional measures of variance based on standard deviation. For example, a female with four 4-day cycles and one 8-day cycle has more regular cycles than a female with one 3-day cycle, two 4-day cycles, one 5-day cycle and one 6-day cycle. The regularity index captures this difference ( $R I=0.6$ and 0.2 respectively). However, the traditional measures of variance indicates that the first female has more variable cycles (S.D. $=1 \cdot 78$ ) than the second (S.D. $=1 \cdot 14$ ). Thus, the two measures are not interrelated and both are necessary to assess the regularity and variability of oestrous cycle length. 
The experimental design avoided confounding effects of age on reproduction and allowed multiple measurements on each individual, but reduced the individual sample size for each month of a single year. Therefore, to document seasonality graphically in the population over 12 months of the year, the average fertility measures were calculated for each month using the individual monthly measures from all rats from which data were collected in that month, whether in the 1 st or 2nd year (following the method of Drickamer, 1984). These population data from the 12 months of the year were double-plotted for each measure to aid visual inspection of the data. Differences in fertility between rats in the winter (October-March) and summer (April-September) were assessed statistically using the Mann-Whitney $U$ test. An independent test was appropriate because each animal was in the summer group $(\mathrm{N}=15)$ or the winter group $(\mathrm{N}=15$; based on the middle data of the individual's vaginal smear record). The division of the year into summer (April-September) and winter (October-March) months was made a priori, based on weather patterns and the reproductive seasonality of Norway rats in the wild (Davis, 1953; Calhoun, 1962). Individuals from the 1 st or 2 nd years followed the seasonal pattern displayed by the population data. In addition a mid-winter (January-February) and mid-summer (June-July) comparison was made for each measure.

\section{Reproductive success measures}

In the second laboratory, reproductive success was measured by the rates of mating, maintaining a successful pregnancy, and raising a litter to weaning. These three measures were recorded for 19 months from over 3000 Wistar rats housed in $12 \mathrm{~L}: 12 \mathrm{D}$ at $21 \pm 2^{\circ} \mathrm{C}$ temperature. Fresh air was drawn into the laboratory, heated or cooled by a central steam unit, moved through the room at 10 room changes per hour and exhausted $100 \%$ to the outside. The relative humidity varied from 60 to $90 \%$ across the year. In neither laboratory were barometric pressure or external air-borne stimuli controlled. About $80 \%$ of the rats were nulliparous and $90-100$ days of age when housed in groups of 5 females and 2 males for mating. The remaining animals were multiparous and 180-210 days of age. The percentage of nulliparous and multiparous females used in the breeding colony was the same throughout the year, although more matings were attempted in the winter months.

Mating was determined by finding spermatozoa in the daily vaginal smears. Mated females were moved to individual cages and were replaced in the group cages on the same day. Females that ceased to cycle or did not become pregnant after 3 weeks in a group cage were also replaced. The number of animals mated is the absolute number of animals in the breeding colony that had spermatozoa in the vaginal tract in that month. To assess the rate of maintaining a successful pregnancy independently of mating rate, we measured the rate of giving birth as the percentage of births per number of mated animals. All litters were reduced to 6 young at $24-48 \mathrm{~h}$ post partum. The final independent measure was the percentage of these culled litters successfully raised to weaning per number of animals giving birth. A litter was defined as successful if any young survived until weaning.

The 19 months of data were plotted with the last 5 months (of 2 nd year) double-plotted to aid visual inspection of the data. The difference between the number of animals reproducing across the 19 months was assessed statistically using a $\chi^{2}$ test, and bimonthly comparisons were made and considered significantly different if $P<0.005$ to account for the repeated post-hoc tests. In addition a mid-winter (January-February) and mid-summer (June-July) comparison was made for each measure for each year.

\section{Results}

All measures of fecundity, except the maintenance of a successful pregnancy, had significant seasonal variation. Fertility and reproductive success peaked between May and August (see Figs 1 

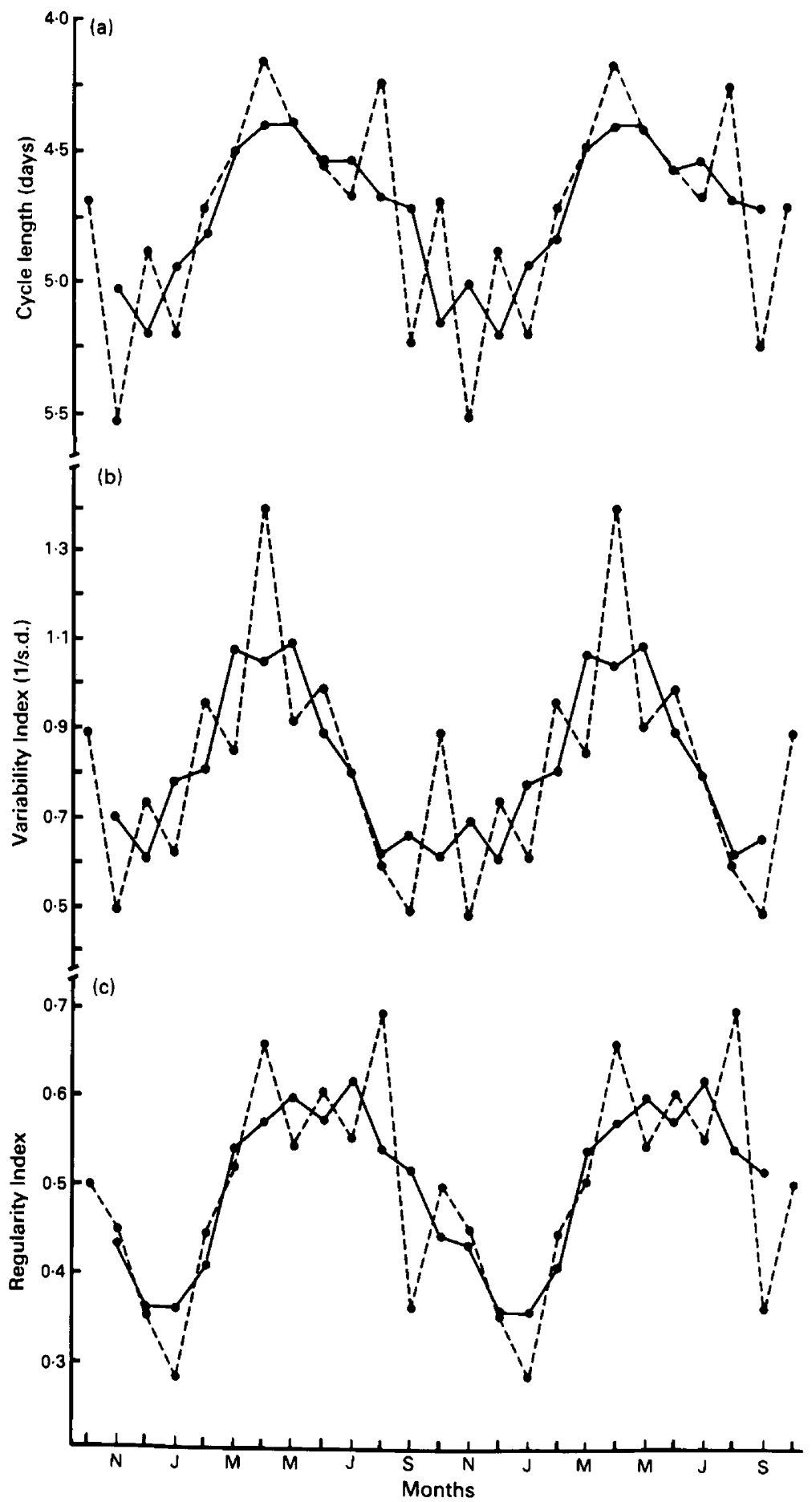

Fig. 1. Double plot of 12-month averages from 2 years of data in Laboratory 1 to show seasonal variation in oestrous cycle length (a), variability of individual cycle length (variability index, 1/s.d.) (b), and regularity of individual oestrous cycle length (regularity index) (c). The broken line represents actual monthly values (all are means of individual values), and the heavy solid line a 3-point moving average. 

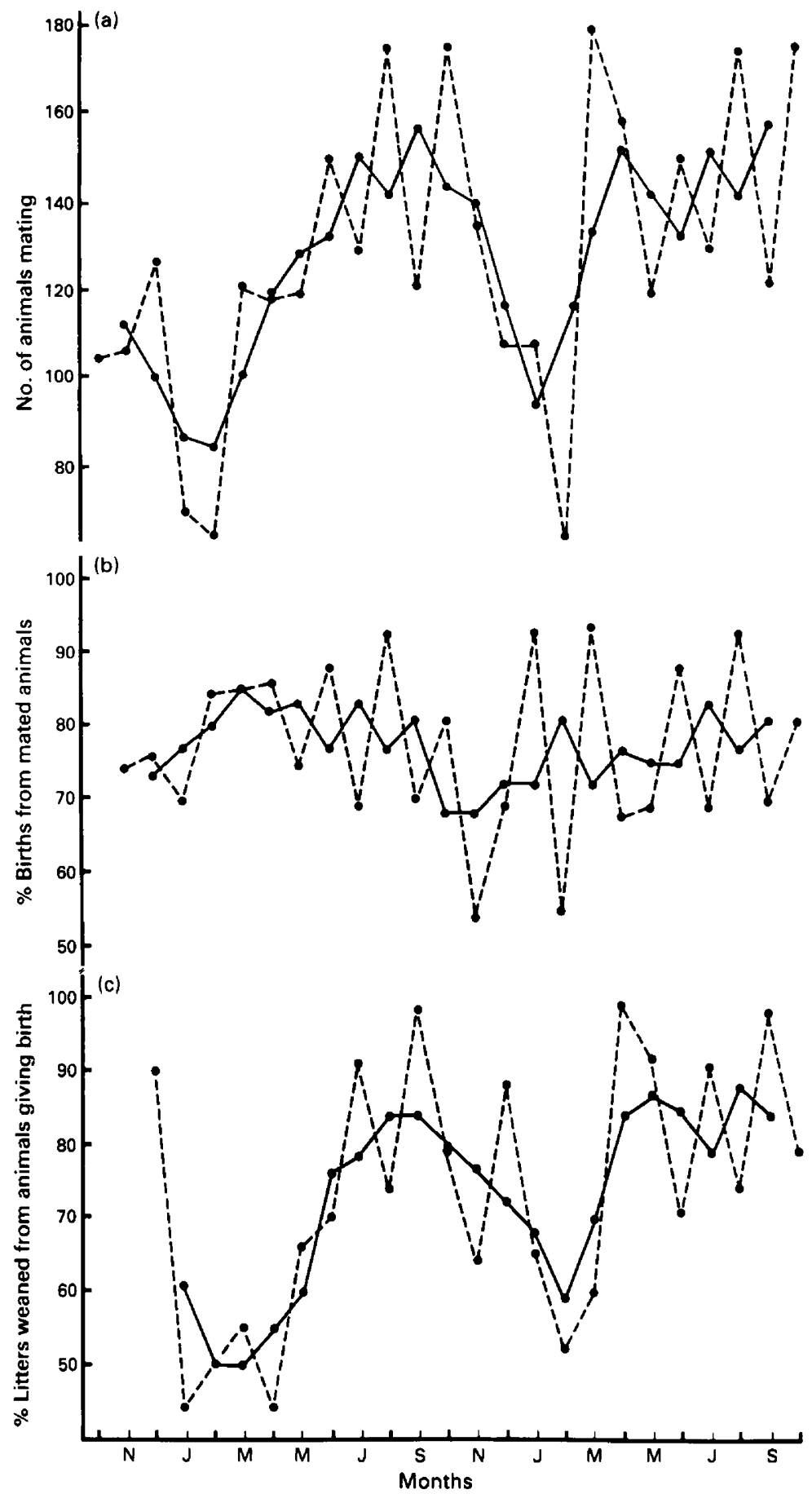

Fig. 2. Data from Laboratory 2, double-plotted for the last 5 months, to show seasonal variation in number of animals mating (a), percentage of mated animals which then gave birth (b), and percentage of animals giving birth which then successfully weaned litters (c). The broken line represents actual monthly values, and the heavy solid line a 3-point moving average. 
$\& 2$ ): oestrous cycles were shorter, less variable and more regular in length than at other times of year; mating and raising litters to weaning were at their highest rates. Fertility and reproductive success as measured by these factors were lowest between December and February.

Winter (October-March) and summer (April-September) months were chosen a priori for statistical comparison of oestrous cycle data based on the seasonal cycle reported for wild populations (Davis, 1953; Calhoun, 1962). Fertility was higher in the summer than in the winter as measured by oestrous cycle length (winter $=5.41 \pm 0.33$, summer $=4.54 \pm 0.16 ; P<0.01$, Mann-Whitney U test), oestrous cycle variability (winter $=0.67 \pm 0.11$, summer $=0.98 \pm 0.13$; $P<0.05$ ) and oestrous cycle regularity (winter $=0.38 \pm 0.05$, summer $=0.58 \pm 0.03 ; P<0.01$ ). In addition, fertility was higher during two summer months (June-July) when days are long and temperatures high than in two winter months (January \& February) when days are short and temperatures low (see Table 1).

The same pattern of mid-summer highs and mid-winter lows was seen for the number of animals mating and percentage litters weaned, but not for percentage of females becoming pregnant (see Table 1). In addition, the nature of the data on reproductive success allowed us to determine that the gradual seasonal rise and fall depicted in Fig. 2 was significant. A bi-monthly analysis for the two measures which displayed overall significant seasonal changes showed a similar pattern for both (at $P<0.005$ or less with $\chi^{2}$ tests, comparing November-December to JanuaryFebruary, January-February to March-April, etc.). There were significant bi-monthly changes during the winter to spring rise and the fall to winter drop in reproductive success, with a high summer plateau (May-August) and low winter plateau (December-February).

Table 1. Significant seasonal variation in fecundity measures of rats

\begin{tabular}{lccccc}
\hline & $\begin{array}{c}\text { January-February } \\
\text { 1st year }\end{array}$ & June-July & Significance & $\begin{array}{c}\text { January-February } \\
\text { 2nd year }\end{array}$ & Significance \\
\hline $\begin{array}{l}\text { Cycle length } \\
\text { (days) }\end{array}$ & 5.25 & 4.40 & $P<0.01^{*}$ & - & - \\
$\begin{array}{l}\text { Variability index } \\
\text { (1/SD) }\end{array}$ & 1.4 & 1.8 & $P<0.01^{*}$ & - & - \\
$\begin{array}{l}\text { Regularity index } \\
\text { No. of animals }\end{array}$ & 0.35 & 0.61 & $P<0.01^{*}$ & - & - \\
$\quad$ mated & 135 & 280 & $P<0.001 \dagger$ & 170 & $P<0.001 \dagger$ \\
$\%$ Giving birth & 77.5 & 79.5 & NS $\dagger$ & 74.5 & NS $\dagger$ \\
$\%$ Litters weaned & 48 & 83 & $P<0.005 \dagger$ & 58.5 & $P<0.05 \dagger$ \\
\hline
\end{tabular}

* Mann-Whitney U test; $\uparrow \chi^{2}$ test.

The figures reveal that the troughs and peaks of the 5 seasonally changing factors occurred within 1 month, even though the data were collected from two different strains of rats housed in separate laboratory buildings. Furthermore, the seasonal variation of these rats in Chicago $\left(42^{\circ} \mathrm{N}\right)$ was similar to that reported for wild rats living under natural conditions in the northern hemisphere between $39^{\circ} \mathrm{N}$ and $54^{\circ} \mathrm{N}$ (King, 1927; Leslie et al., 1952; Davis, 1953; Calhoun, 1962; Telle, 1966).

\section{Discussion}

These data indicate that female, laboratory-dwelling, albino Norway rats display seasonal variations in fecundity as has been previously reported for wild rats. Despite the rigid control of many aspects of laboratory environment, the same seasonal pattern emerged in the two laboratories and, apparently, coincided with the seasonal cycle of free-living rat populations. Changes in photoperiod or temperature can affect reproduction of female and male rats under specific conditions 
(King \& Stotsenburg, 1915; Ohzu \& Sato, 1963; Aguilar, Tejero, Vaticon, Galaz \& Bosch, 1979; Bosc \& Nicolle, 1980a, b; Nelson \& Zucker, 1981; Ramaley, 1981; Wallen \& Turek, 1981; Nelson, Bamat \& Zucker, 1982). Nonetheless, in our laboratories photoperiod was constant, as was temperature. Furthermore, the same pattern emerged despite differences in the constant photoperiods of the two laboratories. Therefore, these environmental variables were unlikely to provide the cues leading to this seasonal pattern. A regular seasonal change of food composition is also an unlikely environmental cue in our laboratories although it may be in others. Our feed suppliers buy and stockpile grain in large quantities according to the commodities market. They report that the time of harvest and the time of processing and distribution of rat chow are generally unrelated and that seasonal variation in composition of food is highly unlikely (Teklad, Inc., Madison, WI, U.S.A.). The tap water originates in Lake Michigan, but is heavily treated throughout the year to remove contaminants.

Although previous studies of male rats indicate that pineal melatonin and brain dopamine are one pathway by which environmental information affects seasonality of the male reproductive system, no attempt was made to determine which aspects of the environment were entraining the animals in these studies (Ying \& Greep, 1973; Balemans et al., 1980; Kafka et al., 1981; Vacas, Sarmiento \& Cardinalli, 1981; Johnson, Vaughan, Richardson, Petterborg \& Reiter, 1982; Prechel et al., 1983; Walker, 1982; Walker, McCammant \& Timiras, 1982; Zisapel, Egozi \& Laudon, 1982, 1983; Zisapel \& Laudon, 1983). Wong et al. (1983) did provide indirect evidence that barometric pressure or air-borne stimuli may be seasonal environmental cues. When these aspects of the laboratory environment were controlled, in addition to light, food, temperature and humidity, seasonal hormonal rhythms in male rats were not observed. Instead, the males had a free-running, endogenous circannual cycles of 6-11 months. Therefore, barometric pressure might have produced the seasonal fecundity of female rats in our study. However, in Chicago, where our laboratories are located, barometric pressure fluctuates widely on a daily basis throughout the year as a result of transitory changes in weather. These wide fluctuations are likely to mask the slight seasonal rhythm, making barometric pressure an unreliable environmental cue for seasonality.

This leaves seasonal chemical or particulate information reaching the rats by unfiltered air systems, human clothing, feed bags and water as possible seasonal environmental cues. In addition, we had sufficient seasonal change in humidity within our laboratories to perhaps account for the results. Nonetheless, the effects of such information on the reproductive system are not known, and we are not yet able to specify how laboratory-housed animals are capable of responding to the season of the year.

The short, regular oestrous cycles in summer and the long variable cycles in winter presumably reflect the female's response to environmental cues. However, the seasonal changes in reproductive success need not result only from female seasonality. Although the low mating rate in winter was brought about by longer and probably infertile cycles in the females, the mating rate in winter may also be reduced by poor male mating activity. Seasonality in male mating behaviour of laboratory housed rats has not been examined systematically, although personal communication from other researchers indicates that this is quite possible and is consistent with seasonality observed in the male neuroendocrine system (Wong et al., 1983). Similarly, the survival rate of litters was reduced in winter largely because winter-breeding females were either unable to lactate, or they cannibalized their litters within $48 \mathrm{~h}$ of birth. However, the reduced survival rate may also reflect poor development of the young. Winter-born young have altered or delayed puberty even in the laboratory (Donovan \& van den Werff ten Bosch, 1959; Ramaley \& Bunn, 1972; Mock et al., 1975; Mock \& Frankel, 1980) although the specific problems with development which could reduce survival to weaning or delay puberty have not been identified.

The environmental cue(s) producing seasonal variations in rats housed in laboratory conditions have yet to be identified. We have suggested the possibility of water, air-borne factors or humidity. It also remains possible that the seasonal variation is based on an endogenous circannual cycle as is seen in male rats. We have suggested that the annual changes in pineal, pituitary and dopamine 
documented in males may also be important for the seasonal variation seen in females. This study also points out the need for a re-examination of the reproductive behaviour and fecundity in different seasons of male rats.

We thank Terri Larson Butler for her assistance with data management and analysis: Dr Howard Moltz for support while data from 'Laboratory 2' were collected from his animals; and Dr Irv Zucker for comments on the manuscript. This research was supported by PHS S07RR0729 from the National Institute of Child Health and Human Development to Dr H. Moltz and by PHS 5 RR3AG02408 from the National Institute of Aging (M.K.M.) and by 80-19496 from the National Science Foundation (M.K.M.).

\section{References}

Aguilar, E., Tejero, A., Vaticon, M.A., Galaz, C.F. \& Bosch, A.O. (1979) Effects of photoperiods on LH and prolactin (PRL) plasma levels in the male rat. $J$. Steroid Biochem. 11, 1499-1502.

Ahlers, I., Ablersova, E., Daxnorova, Z., Toropila, M. \& Smajda, B. (1982) Influence of the season on the circadian rhythm of serum lipids in male Wistar rats. Physiol. Bohemoslav. 31, 65-73.

Ahlersova, E., Ahlers, I., Toropila, M. \& Smajda, B. (1982) Influence of the seasons on the circadian rhythm of blood glucose and tissue glycogen in male Wistar rats. Physiol. Bohemoslav. 31, 45-55.

Balemans, M.G.M., Bary, F.A.M., Legerstee, W.C. \& van Benthem, J. (1980) Seasonal variations in HIOMT activity during the night in the pineal gland of 21 day old male Wistar rats. J. Neural Transmission 49, 107-116.

Berger, J. (1981) Seasonal influence on circadian variations in blood picture of laboratory rats. Zwierzeta Laboratoryjne. 18, 3-25.

Bosc, M.J. \& Nicolle, A. (1980a) Influence of photoperiod on the time of parturition in the rat. I. Effect of the length of daily illumination on normal or adrenalectomized animals. Reprod. Nutr. Develop. 20, 735-745.

Bosc, M.J. \& Nicolle, A. (1980b) Influence of photoperiod on the time of parturition in the rat. II. Demonstration of a photoinducible phase and determination of some of its characteristics. Reprod. Nutr. Develop. 20, 939-948.

Butcher, R.L. \& Page, R.D. (1981) Role of the aging ovary in cessation of reproduction. In Dynamics of Ovarian Function, pp. 253-271. Eds N. B. Schwartz \& M. Hunzicker-Dunn. Raven Press, New York.

Calhoun, J.B. (1962) The Ecology and Sociology of the Norway Rat. U.S. Dept of Health Education and Welfare, Bethesda.

Davis, D.E. (1953) The characteristics of rat populations. Q. Rev. Biol. 28, $373-401$.

Davis, D.E. \& Hall, O. (1951) The seasonal reproductive condition of female Norway (brown) rats in Baltimore, Maryland. Physiol. Zool. 21, 9-20.

Drickamer, L.C. (1984) Seasonal variation in acceleration and delay of sexual maturation in female mice by urinary chemosignals. J. Reprod. Fert. $\mathbf{7 2}$, $55-58$.
Donovan, B.T. \& van den Werff ten Bosch, J.J. (1959) The hypothalamus and sexual maturation in the rat. $J$. Physiol., Lond. 147, 78-92.

Gerall, A.A. \& Dunlap, J.L. (1973) Time dependent changes induced by neonatal androgen. Society for Neuroscience, BIS Conference, Rep. No. 15, pp. 38-41.

Gerall, A.A., Dunlap, J.L. \& Sonntag, W.E. (1980) Reproduction in aging normal and neonatally androgenized rats. J. comp. Physiol. Psych. 94, 556-563.

Illnerova, H. \& Vanecek, J. (1980) Pineal rhythm in $\mathrm{N}$-acetyltransferase activity in rats under different artificial photoperiods and natural daylight in the course of a year. Neuroendocrinology 31, 321-326.

Johnson, L.Y., Vaughan, M.K., Richardson, B.A., Petterborg, L.J. \& Reiter, R.J. (1982) Variation in pineal melatonin content during the estrous cycle of the rat. Proc. Soc. exp. Biol. Med. 169, 416-419.

Kafka, M.S., Wirz-Justice, A. \& Naber, D. (1981) Circadian and seasonal rhythms in a- and Badrenergic receptors in the rat brain. Brain Res. 207, 409-419.

King, H.D. (1927) Seasonal variations in fertility and in the sex ratio of mammals, with special reference to the rat. Wilhelm Roux. Arch. EntwMech. Org. 112, 62-112.

King, H.D. \& Stotsenburg, J.M. (1915) On the normal sex ratio and the size of the litter in the albino rat (Mus norvegicus albinus). Anat. Rec. 9, 403-420.

Leslie, P.H., Venables, U.M. \& Venables, L.S. (1952) The fertility and population structure of the brown rat (Rattus norvegicus) in cornricks and some other habitats. Proc. Zool. Soc. Lond. 122, 187-238.

McClintock, M.K. (1983) Modulation of estrous cycle by pheromones from pregnant and lactating rats. Biol. Reprod. 28, 823-829.

Minckler, J. \& Pease, F.D. (1938) A colony of albino rats existing under feral conditions. Science, N.Y. 87, $460-461$.

Mock, E.J. \& Frankel, A.I. (1978) A seasonal influence on testes weight and serum gonadotropin levels of the mature male laboratory rat. Biol. Reprod. 17, 772-778.

Mock, E.J. \& Frankel, A.I. (1980) Influence of month of birth on the serum hormone concentrations and 
weights of accessory sex organs and testes during maturation of the male laboratory rat. Biol. Reprod. 22, 119-133.

Mock, E.J., Kamel, F., Wright, W.W. \& Frankel, A.I. (1975) Seasonal rhythm in plasma testosterone and luteinizing hormone of the male laboratory rat. Nature, Lond. 256, 61-63.

Nelson, R.J. \& Zucker, I. (1981) Photoperiodic control of reproduction in olfactory-bulbectomized rats. Neuroendocrinology 32, $266-271$.

Nelson, R.J., Bamat, M.K. \& Zucker, I. (1982) Photoperiodic regulation of testis function in rats: mediation by a circadian mechanism. Biol. Reprod. 26, 329-335.

Ohzu, E. \& Sato, A. (1963) Breeding experiments of white rats and mice. IX. Seasonal variation of birthrate and litter size for several strains of laboratory rats. Zool. Mag. 72, 139-145.

Prechel, M.M., Audhya, T.K. \& Schlesinger, D.H. (1983) A seasonal variation in arginine vasotocin immunoreactivity in rat pineal glands. Endocrinology 112, $1474-1478$.

Ramaley, J.A. (1981) Serum prolactin levels in the prepubertal period in male and female rats. Control by photoperiod and gonadal status and relationship to puberty onset. Int. J. Androl. 4, 9!-104.

Ramaley, J.A. \& Bunn, E.L. (1972) Seasonal variations in the onset of puberty in rats. Endocrinology 91, $61 \mathrm{I}-613$.

Telle, H.J. (1966) Beitrag zur Kenntnis der Verhaltensweise von Ratten, Vergleichend dargstellt bei Rattus norvegicus und Rattus rattus. $Z$. angew. Zool. 53, 129-196.

Vacas, M.I., Sarmiento, M.I.K. \& Cardinalli, D.P. (1981) Melatonin increases cGMP and decreases cAMP levels in rat medial basal hypothalamus in vitro. Brain Res. 225, 207-211.
Vanecek, J. \& Illnerova, H. (1982) Effect of photoperiod on the growth of reproductive organs and on pineal $\mathrm{N}$-acetyltransferase rhythm in male rats treated neonatally with testosterone propionate. Biol. Reprod. 27, 517-522.

Walker, R.F. (1982) Melatonin: Serotonin interaction during termination of the $\mathrm{LH}$ surge in rats. In The Pineal and its Hormones, pp. 167-176. Ed. R. J. Reiter. Alan R. Liss, Inc., New York.

Walker, R.F., McCammant, S. \& Timiras, P.S. (1982) Melatonin and the influence of the pineal gland on timing of the LH surge in rats. Neuroendocrinology 35, 37-42.

Wallen, E.P. \& Turek, F.W. (1981) Photoperiodicity in the male albino laboratory rat. Nature, Lond. 289 , $402-404$.

Wong, C.C., Dohler, K.-D., Atkinson, M.J., Geerlings, H., Hesch, R.-D. \& van zur Muhlen, A. (1983) Circannual variations in serum concentrations or pituitary, thyroid, parathyroid, gonadal and adrenal hormones in male laboratory rats. J. Endocr. 97 , 179-185.

Ying, S.-Y. \& Greep, R.O. (1973) Inhibition of ovulation by melatonin in the cyclic rat. Endocrinology 92 , 333-335.

Zisapel, N. \& Laudon, M. (1983) Inhibition by melatonin of dopamine release from rat hypothalamus: regulation of calcium entry. Brain Res. 272, 378-381.

Zisapel, N., Egozi, Y. \& Laudon, M. (1982) Inhibition of dopamine release by melatonin: regional distribution in the rat brain. Brain Res. 246, 161-163.

Zisapel, N., Egozi, Y. \& Laudon, M. (1983) Inhibition by melatonin of dopamine release from rat hypothalamus in vitro: variations with sex and the estrous cycle. Neuroendocrinology 37, 41-47.

Received 8 May 1985 